Check for updates

Cite this: Mater. Adv., 2020, 1,1262

Received 10th May 2020,

Accepted 30th June 2020

DOI: 10.1039/d0ma00294a

rsc.li/materials-advances

\title{
Influence of different bismuth oxyhalides on the photocatalytic activity of graphitic carbon nitride: a comparative study under natural sunlight $\uparrow$
}

\author{
Mahender Singh, $\ddagger$ Ashish Kumar (D) $\ddagger$ and Venkata Krishnan (D)*
}

\begin{abstract}
The light harvesting properties and charge separation in the trending graphitic carbon nitride $\left(\mathrm{g}-\mathrm{C}_{3} \mathrm{~N}_{4}\right)$ material have been widely explored to enhance its photocatalytic performance employing doping, morphology control and composite formation. Herein, the effect of coupling of different bismuth oxyhalides, $\mathrm{BiOX}(\mathrm{X}=\mathrm{F}, \mathrm{Cl}, \mathrm{Br}$ and $\mathrm{I})$, on the photocatalytic performance of $\mathrm{g}-\mathrm{C}_{3} \mathrm{~N}_{4}$ has been studied by synthesizing $\mathrm{BiOX} / \mathrm{g}-\mathrm{C}_{3} \mathrm{~N}_{4}$ composites by a facile hydrothermal method. It was found that the BiOX/ g- $\mathrm{C}_{3} \mathrm{~N}_{4}$ composites showed enhanced photocatalytic degradation of a model pollutant, Congo red dye, under natural sunlight irradiation, as compared to the bare $\mathrm{g}-\mathrm{C}_{3} \mathrm{~N}_{4}$ and respective BiOX. The enhanced photocatalytic performance of the composites was attributed to the appropriate band edge potential and better interfacial contact between $\mathrm{g}-\mathrm{C}_{3} \mathrm{~N}_{4}$ and $\mathrm{BiOX}$, which suppresses charge recombination and allows their better utilization at catalytic sites than in the case of bare $\mathrm{g}-\mathrm{C}_{3} \mathrm{~N}_{4}$ and respective BiOX. In comparison to all the BiOX/g- $\mathrm{C}_{3} \mathrm{~N}_{4}$ composites, BiOBr/g- $\mathrm{C}_{3} \mathrm{~N}_{4}$ showed the degradation of Congo red at a higher rate and was also found to be effective for the degradation of a colorless fungicide, carbendazim. Further, to look into the role of the active species responsible for this activity, trapping experiments have been carried out, which revealed that $\mathrm{OH}^{*}$ was the main reactive species in the degradation process and, based on these results, a suitable mechanism for the enhanced photocatalytic activity has been proposed and discussed. Hence, the BiOX/g- $\mathrm{C}_{3} \mathrm{~N}_{4}$ composite formation has proven beneficial for achieving high photocatalytic performance and provides new insight on bismuth oxyhalides and $\mathrm{g}-\mathrm{C}_{3} \mathrm{~N}_{4}$ based photocatalysts for environmental remediation application.
\end{abstract}

\section{Introduction}

Currently, the world is facing tremendous environmental problems, especially related to water pollution, as a result of the waste disposal in water reservoirs by many industries. ${ }^{1,2}$ Particularly, the effluent from textile industries mainly contains toxic organic dyes, which is one of the major contributors of water pollution. Azo dyes possess good stability due to their aromaticity and are non-biodegradable with carcinogenic properties. Therefore, the release of these toxic chemicals without proper treatment in water reservoirs is highly dangerous for aquatic life as well as to human health because they interfere in the food chain. In this regard, several efforts have been made by using strategies such as adsorption of organic pollutants by using conventional adsorbents, like silica, activated charcoal and advanced metal organic framework (MOF) materials.

School of Basic Sciences and Advanced Materials Research Center, Indian Institute of Technology Mandi, Kamand, Mandi 175075, Himachal Pradesh, India.

E-mail: vkn@iitmandi.ac.in

$\dagger$ Electronic supplementary information (ESI) available. See DOI: 10.1039/d0ma00294a

\$ These authors contributed equally to this work.
However, the adsorption technique is not very effective as it causes secondary pollution during the recycling of adsorbents. ${ }^{3,4}$ On the contrary, the use of heterogeneous photocatalysis for the degradation of organic pollutants in the presence of light irradiation has emerged as an alternative environmentally benign solution for this problem. The use of sunlight as a source for this process, good degradation of pollutants and excellent recyclability of photocatalysts are the key advantages of this process, which makes it a sustainable approach.

In the past few decades, several oxides, sulfides and other semiconductor based materials have been reported for photocatalytic degradation of organic pollutants. ${ }^{5-8}$ Recently, the organic semiconducting material graphitic carbon nitride $\left(g-\mathrm{C}_{3} \mathrm{~N}_{4}\right)$ has gained much importance due to its unique properties, like high thermal stability, earth-abundant elements, low cost and efficient light absorption. ${ }^{9}$ The band gap of $\mathrm{g}-\mathrm{C}_{3} \mathrm{~N}_{4}$ is around $2.7 \mathrm{eV}$ and it can harvest visible light effectively. However, the photocatalytic performance of $\mathrm{g}-\mathrm{C}_{3} \mathrm{~N}_{4}$ is restricted due to the high recombination rate of photogenerated charges and lower surface area. Therefore, to improve the photocatalytic performance of this material, various 
strategies have been employed to suppress charge recombination and to enhance the surface area and light absorption. ${ }^{10}$ In this regard, template-assisted synthesis of mesoporous $\mathrm{g}-\mathrm{C}_{3} \mathrm{~N}_{4}$ along with metal and non-metal doped $\mathrm{g}-\mathrm{C}_{3} \mathrm{~N}_{4}$ have been reported by researchers to enhance the photocatalytic activity. ${ }^{11-14}$ Another interesting approach for increasing the photocatalytic performance of $\mathrm{g}-\mathrm{C}_{3} \mathrm{~N}_{4}$ is coupling it with another semiconducting material having suitable band positions, which can in turn enhance the charge separation and boost the photocatalytic performance. ${ }^{15}$ For example, Shi et al. have reported the synthesis of a $\mathrm{MoS}_{2} /$ protonated $\mathrm{g}-\mathrm{C}_{3} \mathrm{~N}_{4}$ nanosheet composite for the degradation of methyl orange and phenol under visible light irradiation. ${ }^{16}$ Ma et al. have synthesized type-II $\mathrm{CeO}_{2} / \mathrm{g}-\mathrm{C}_{3} \mathrm{~N}_{4}$ nanosheets for the visible light induced degradation of bisphenol A. ${ }^{17}$ Our group has also reported $\mathrm{CaTiO}_{3} / \mathrm{g}-\mathrm{C}_{3} \mathrm{~N}_{4}{ }^{18}$ and $\mathrm{N}$-doped $\mathrm{ZnO} / \mathrm{g}-\mathrm{C}_{3} \mathrm{~N}_{4}{ }^{19}$ composite photocatalysts for efficient degradation of diverse industrial pollutants. Several other composite materials, such as core-shell $\mathrm{TiO}_{2} @ g-\mathrm{C}_{3} \mathrm{~N}_{4},{ }^{20} \mathrm{WO}_{3} /$ g- $\mathrm{C}_{3} \mathrm{~N}_{4},{ }^{21} \mathrm{MnO}_{2} / \mathrm{g}-\mathrm{C}_{3} \mathrm{~N}_{4},{ }^{22} \mathrm{Ag}_{3} \mathrm{PO}_{4} / \mathrm{g}-\mathrm{C}_{3} \mathrm{~N}_{4},{ }^{23} \mathrm{CdS} / \mathrm{RGO} / \mathrm{g}-\mathrm{C}_{3} \mathrm{~N}_{4},{ }^{24}$ etc., have been also reported for photocatalytic pollutant degradation. In each case, the composite materials have shown enhanced photocatalytic activity in comparison to the bare components, which mainly arose from the efficient transfer and suppressed recombination of photogenerated charges. Hence, the combination of two different materials with suitable band edge potentials can result in enhanced photocatalytic activity by suppressing electron-hole pair recombination.

In addition to the different semiconducting materials mentioned above, bismuth oxyhalides (BiOX, $\mathrm{X}=\mathrm{F}, \mathrm{Cl}, \mathrm{Br}$ and I) are also of great interest in photocatalysis owing to their good optical properties. The band gap of BiOX lies in the range of 3.5-3.6 eV, 2.9-3.4 eV, 2.3-2.9 eV and 1.8-2.1 eV for BiOF, $\mathrm{BiOCl}, \mathrm{BiOBr}$, and BiOI, respectively, which enables them to harvest the UV and visible regions of light. ${ }^{25}$ Moreover, the band edge positions of BiOX are suitable for their coupling with $\mathrm{g}-\mathrm{C}_{3} \mathrm{~N}_{4}$ and high photocatalytic performance as a result of suppressed photogenerated charge recombination can be anticipated from the resulting composite materials. Therefore, to explore the possibilities of increasing the photocatalytic activity of BiOX and $\mathrm{g}-\mathrm{C}_{3} \mathrm{~N}_{4}$, we have synthesized the composites of each BiOX ( $\mathrm{X}=\mathrm{F}, \mathrm{Cl}, \mathrm{Br}$ and $\mathrm{I})$ with $\mathrm{g}-\mathrm{C}_{3} \mathrm{~N}_{4}$ by a simple hydrothermal method with a $1: 1 \mathrm{wt} \%$ ratio. The photocatalytic activity of the as-prepared composites was measured by monitoring the degradation of a model organic pollutant, Congo red (CR), under natural sunlight irradiation. Also, the degradation of a colorless and non-photosensitizing fungicide, carbendazim (CBZ), was studied to reveal the true activity of the photocatalyst. It has been evidenced that the formation of the composite can efficiently boost the charge transfer between BiOX and $\mathrm{g}^{-} \mathrm{C}_{3} \mathrm{~N}_{4}$ through intimate interfaces and high photocatalytic performance towards the degradation of CR and CBZ. In addition, the influence of the different BiOX on the photocatalytic activity of $\mathrm{g}-\mathrm{C}_{3} \mathrm{~N}_{4}$ has also been investigated under natural sunlight irradiation. Overall, it can be ascertained that BiOX-g- $\mathrm{C}_{3} \mathrm{~N}_{4}$ composites are well suited for the efficient photocatalytic degradation of organic pollutants in waste water.

\section{Experimental section}

\subsection{Chemicals}

Bismuth(III) nitrate pentahydrate $\left(\mathrm{Bi}\left(\mathrm{NO}_{3}\right)_{3} \cdot 5 \mathrm{H}_{2} \mathrm{O}\right)$, dicyandiamide, potassium iodide and sodium chloride were purchased from Sigma Aldrich, India, and were used as received. Potassium hydrogen difluoride and glacial acetic acid were purchased from SD Fine Chemicals, India, and potassium bromide was provided by Merck, India. Deionized (DI) water was used in all the experiments and was obtained from a double-stage water purifier (ELGA PURELAB Option-R7).

\subsection{Material preparation}

2.2.1 Synthesis of graphitic carbon nitride $\left(\mathrm{g}-\mathrm{C}_{3} \mathrm{~N}_{4}\right)$. The synthesis of $\mathrm{g}-\mathrm{C}_{3} \mathrm{~N}_{4}$ was carried out by thermal polymerization of dicyandiamide by following a previously reported procedure. ${ }^{18}$ Typically, $5 \mathrm{~g}$ dicyandiamide was placed in an alumina crucible and initially heated at $550{ }^{\circ} \mathrm{C}$ with a ramp rate of $3{ }^{\circ} \mathrm{C}$ per min for $4 \mathrm{~h}$. The obtained yellow solid mass was then ground to obtain a fine powder as bulk g- $\mathrm{C}_{3} \mathrm{~N}_{4}$. For the synthesis of $\mathrm{g}-\mathrm{C}_{3} \mathrm{~N}_{4}$ nanosheets, the obtained powder from the first step of heating was again treated at $500{ }^{\circ} \mathrm{C}$ for $2 \mathrm{~h}$ with a ramp rate of $5{ }^{\circ} \mathrm{C}$ per min. The final product as a pale yellow powder was obtained and used for further characterization and the synthesis of composites.

2.2.2 Synthesis of BiOF. BiOF was synthesized by using bismuth(III) nitrate pentahydrate $\left(\mathrm{Bi}\left(\mathrm{NO}_{3}\right)_{3} \cdot 5 \mathrm{H}_{2} \mathrm{O}\right)$ and potassium hydrogen difluoride $\left(\mathrm{KHF}_{2}\right)$ as precursors using the hydrothermal method. ${ }^{26}$ Initially, 2 mmol of $\mathrm{Bi}\left(\mathrm{NO}_{3}\right)_{3} \cdot 5 \mathrm{H}_{2} \mathrm{O}$ was dissolved in 40 $\mathrm{mL}$ DI water and stirred for $15 \mathrm{~min}$ to get a suspension. Then, $2 \mathrm{mmol}$ of $\mathrm{KHF}_{2}$ was added to the suspension and sonicated for 15 min. The resultant mixture was transferred to a Teflon lined stainless steel autoclave and the reaction was kept for $6 \mathrm{~h}$ at $150{ }^{\circ} \mathrm{C}$ in an oven. After cooling to room temperature, the resultant product was centrifuged and washed with ethanol and DI water thrice, and then dried in an oven at $80{ }^{\circ} \mathrm{C}$ to obtain a white powder.

2.2.3 Synthesis of BiOCl. Similar to a previously reported procedure, ${ }^{26}$ for hydrothermal synthesis of BiOCl, $2 \mathrm{mmol}$ $\mathrm{Bi}\left(\mathrm{NO}_{3}\right)_{3} \cdot 5 \mathrm{H}_{2} \mathrm{O}$ was dissolved in $40 \mathrm{~mL}$ DI water and stirred for $15 \mathrm{~min}$ to get a suspension. To this suspension, $2 \mathrm{mmol}$ $\mathrm{NaCl}$ was added and the mixture was sonicated for $15 \mathrm{~min}$. The reaction mixture was then transferred to a Teflon coated stainless steel autoclave and the reaction was kept at $150{ }^{\circ} \mathrm{C}$ for $6 \mathrm{~h}$ in an oven. The resultant product was centrifuged and washed with ethanol and DI water thrice and dried in an oven at $80{ }^{\circ} \mathrm{C}$ to obtain a white colored powder.

2.2.4 Synthesis of BiOBr. For this synthesis, a previously reported procedure was followed. ${ }^{27}$ In brief, $2 \mathrm{mmol}$ of $\mathrm{Bi}\left(\mathrm{NO}_{3}\right)_{3}$. $5 \mathrm{H}_{2} \mathrm{O}$ was dissolved in $3 \mathrm{~mL}$ acetic acid (glacial) and stirred to get a suspension. This suspension was mixed slowly with $2 \mathrm{mmol} \mathrm{KBr}$ solution which was prepared in $30 \mathrm{~mL}$ DI water with constant stirring. The reaction mixture after complete mixing was transferred to a Teflon coated stainless steel autoclave and the reaction was kept for $24 \mathrm{~h}$ at $120{ }^{\circ} \mathrm{C}$ in an oven. The obtained product was centrifuged and washed with ethanol and DI water thrice to remove impurities from the sample. The final product was dried in an oven overnight at $80{ }^{\circ} \mathrm{C}$ to obtain a white powder. 
2.2.5 Synthesis of BiOI. For the hydrothermal synthesis of BiOI, two different solutions were prepared as the first step. Solution A contains $2 \mathrm{mmol}$ of $\mathrm{Bi}\left(\mathrm{NO}_{3}\right)_{3} \cdot 5 \mathrm{H}_{2} \mathrm{O}$ dissolved in $17 \mathrm{~mL}$ ethanol and solution $\mathrm{B}$ was prepared by dissolving $2 \mathrm{mmol}$ of $\mathrm{KI}$ in $17 \mathrm{~mL}$ DI water. In the next step, solution B was slowly added to solution A to obtain a yellow suspension, which changes to wine red with completion of addition under constant stirring. The resultant solution was transferred to a Teflon coated stainless steel autoclave and the reaction was kept at $160{ }^{\circ} \mathrm{C}$ for $24 \mathrm{~h}$. After cooling, the obtained product was centrifuged and washed with ethanol and DI water thrice. The product was dried overnight in an oven at $80{ }^{\circ} \mathrm{C}$ to obtain a red colored powder.

2.2.6 Synthesis of BiOX $/ \mathbf{g}-\mathrm{C}_{3} \mathbf{N}_{4}$ composites. For the synthesis of composites of each $\mathrm{BiOX}(\mathrm{X}=\mathrm{F}, \mathrm{Cl}, \mathrm{Br}$ and $\mathrm{I})$ with $\mathrm{g}-\mathrm{C}_{3} \mathrm{~N}_{4}$, an equivalent amount of each component $(1: 1 \mathrm{wt} \%$ ratio) was used. Two different reaction mixtures were prepared, wherein mixture A was prepared by dispersing $0.2 \mathrm{~g}$ of BiOX in $20 \mathrm{~mL}$ DI water and mixture B was prepared by dispersing $0.2 \mathrm{~g}$ of $\mathrm{g}-\mathrm{C}_{3} \mathrm{~N}_{4}$ in $20 \mathrm{~mL}$ DI water. Both the mixtures were separately sonicated for $1 \mathrm{~h}$ to ensure good dispersion and then mixed. Subsequently, the final mixture was again sonicated for $1 \mathrm{~h}$ to ensure good mixing of both components. The final suspension formed after completion of sonication was transferred to a Teflon coated stainless steel autoclave and the reaction was kept at $150{ }^{\circ} \mathrm{C}$ for $24 \mathrm{~h}$ in an oven. After cooling the autoclave, the obtained product was centrifuged and washed with ethanol and DI water thrice and dried in an oven at $80{ }^{\circ} \mathrm{C}$ to obtain the final composite.

\subsection{Evaluation of the photocatalytic activity}

To study the photocatalytic performance of the as prepared photocatalysts, the degradation of a model dye, Congo red (CR), was carried out under natural sunlight irradiation. The degradation experiments were performed in a $50 \mathrm{~mL}$ conical flask by using $20 \mathrm{~mL}$ of a $5 \times 10^{-5} \mathrm{M}$ aqueous solution of CR dye along with $20 \mathrm{mg}$ of catalyst for each experiment. To achieve the adsorptiondesorption equilibrium of CR over the photocatalytic materials, the $\mathrm{CR}$ and photocatalyst mixture was magnetically stirred under dark conditions for $30 \mathrm{~min}$. The concentration of $\mathrm{CR}$ dye after attaining the adsorption-desorption equilibrium was taken as the initial concentration $\left(C_{0}\right)$ in each case. Subsequently, the suspension was irradiated under natural sunlight having a light intensity of 85000-90000 lux, with constant magnetic stirring for $90 \mathrm{~min}$. For every $15 \mathrm{~min}$ interval, $1 \mathrm{~mL}$ solution from the suspension was taken out and centrifuged to separate the catalyst and the supernatant obtained was used to monitor the degradation of CR as a function of time. Furthermore, the degradation of a colorless pollutant, carbendazim (CBZ), was also studied under natural sunlight irradiation using the best catalyst from the previous experiments, to ascertain the true photocatalytic activity of the catalyst and to exclude any possible contributions due to photosensitization. In this regard, $20 \mathrm{~mL}$ CBZ solution of $2 \times 10^{-5} \mathrm{M}$ concentration was taken along with $20 \mathrm{mg}$ of the catalyst and all other conditions were kept the same as for the degradation of CR dye. The percentage degradation rate of CR and CBZ was calculated by applying the following formula: ${ }^{7}$

$$
\mathrm{DR}_{\text {Pollutant }}=\left(1-C_{t} / C_{0}\right) \times 100
$$

Here $C_{0}$ is the initial concentration of the pollutant and $C_{t}$ is the concentration after sample irradiation.

\section{Results and discussion}

\subsection{Synthesis and structural studies}

The synthesis of $\mathrm{g}-\mathrm{C}_{3} \mathrm{~N}_{4}$ nanosheets was performed using the thermal polymerization technique and the synthesis of various BiOX materials was performed using the hydrothermal method. The synthesis procedure of $\mathrm{g}-\mathrm{C}_{3} \mathrm{~N}_{4}$ and $\mathrm{BiOX}$ is presented in Scheme 1 . The synthesis of various $\mathrm{BiOX} / \mathrm{g}-\mathrm{C}_{3} \mathrm{~N}_{4}$ composites in a $1: 1 \mathrm{wt} \%$ ratio was also performed using the hydrothermal method, as depicted in Scheme 2. After the synthesis, the purity and crystal structure of $\mathrm{g}-\mathrm{C}_{3} \mathrm{~N}_{4}, \mathrm{BiOX}$ and the $\mathrm{BiOX} / \mathrm{g}-\mathrm{C}_{3} \mathrm{~N}_{4}$ composites were confirmed by studying the PXRD patterns as presented in Fig. 1. The PXRD pattern of $\mathrm{g}-\mathrm{C}_{3} \mathrm{~N}_{4}$ shows an intense peak at $2 \theta=27.40^{\circ}$, which can be assigned to the (002) plane and corresponds to the interplanar stacking of the aromatic structures in $\mathrm{g}-\mathrm{C}_{3} \mathrm{~N}_{4}$. The other peak at $2 \theta=13.15^{\circ}$ (001) exhibits lesser intensity and corresponds to the in-plane structural motif packing in $\mathrm{g}-\mathrm{C}_{3} \mathrm{~N}_{4} \cdot{ }^{18,28}$ On the other hand, the PXRD patterns of BiOF (JCPDS No. 73-1595), ${ }^{29} \mathrm{BiOCl}$ (JCPDS No. 85-0861), ${ }^{30}$ BiOBr (JCPDS No. 73-2061) ${ }^{31}$ and BiOI (JCPDS No. 73-2062) ${ }^{29}$ were well matched with their respective JCPDS data and confirm their successful formation as shown in Fig. 1a. All the assigned planes to diffraction peaks confirm the tetragonal crystal structure of the respective bismuth oxyhalides with high purity. ${ }^{30}$ The major diffraction peaks of different planes of the BiOX crystal lattice could also be evidenced in the PXRD patterns of the BiOX/g- $\mathrm{C}_{3} \mathrm{~N}_{4}$ composites (Fig. 1b), wherein the presence of $g-\mathrm{C}_{3} \mathrm{~N}_{4}$ can be confirmed from its (002) diffraction peak and the absence of the (001) peak was also noticed because of its weak diffraction intensity. In addditon, the crystallite size is also calculated by using the Scherrer formula $^{32}$ for the pristine samples and was found to be $3.5 \mathrm{~nm}$, $67.0 \mathrm{~nm}, 48.9 \mathrm{~nm}, 61.7 \mathrm{~nm}$, and $3.68 \mathrm{~nm}$ for $\mathrm{g}-\mathrm{C}_{3} \mathrm{~N}_{4}, \mathrm{BiOF}, \mathrm{BiOCl}$, $\mathrm{BiOBr}$ and BiOI, respectively.

The FTIR spectra for all prepared samples were also examined for investigating the various functionalities and the corresponding results are depicted in Fig. 2. The FTIR spectra of g- $\mathrm{C}_{3} \mathrm{~N}_{4}$ show peaks for the out-of-plane bending vibration of the heptazine ring at $804 \mathrm{~cm}^{-1}$ and for the stretching vibration of connected unit C-N-(C)-C and C-NH-C at 1318 and $1226 \mathrm{~cm}^{-1}$, respectively. The stretching vibrations of heptazine derivative repeating units are assigned to the peaks at wavenumber 1630, 1555 and $1405 \mathrm{~cm}^{-1}$. The broad peak from $3000-3400 \mathrm{~cm}^{-1}$ corresponds to the $\mathrm{N}-\mathrm{H}$ stretching frequency of heptazine and triazine rings of $\mathrm{g}^{-} \mathrm{C}_{3} \mathrm{~N}_{4} \cdot{ }^{33}$ In the case of different bismuth oxyhalides, the characteristic $\mathrm{Bi}-\mathrm{O}$ vibrational stretching frequency peaks were evidenced at 484, 511, 525 and $538 \mathrm{~cm}^{-1}$ for $\mathrm{BiOF}, \mathrm{BiOCl}, \mathrm{BiOBr}$, and BiOI, respectively. ${ }^{34-37}$ The FTIR spectra 
(a)

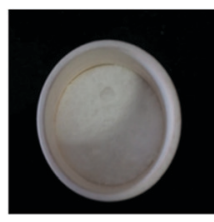

Dicyandiamide

(b)

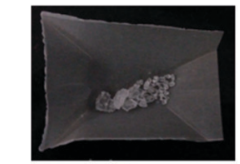

$\mathrm{Bi}\left(\mathrm{NO}_{3}\right)_{3} \cdot 5 \mathrm{H}_{2} \mathrm{O}(2 \mathrm{mmol})$

$+$

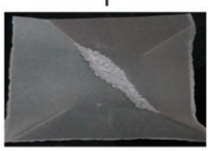

NaX or KX (2 mmol)
Heated at $550^{\circ} \mathrm{C}$ for $4 h$

$40 \mathrm{~mL}$ DI water,

$10 \mathrm{~min}$ ultrasonication

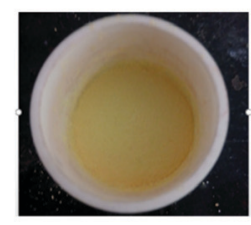

Bulk g- $\mathrm{C}_{3} \mathrm{~N}_{4}$

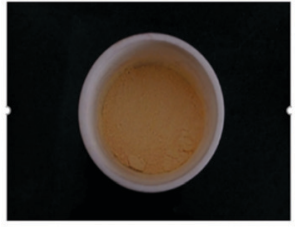

g- $C_{3} N_{4}$ Nanosheets

Scheme 1 Schematic representation of the synthesis of (a) $\mathrm{g}-\mathrm{C}_{3} \mathrm{~N}_{4}$ and (b) hydrothermal synthesis of $\mathrm{BiOX}(\mathrm{X}=\mathrm{F}, \mathrm{Cl}, \mathrm{Br}$ and I).
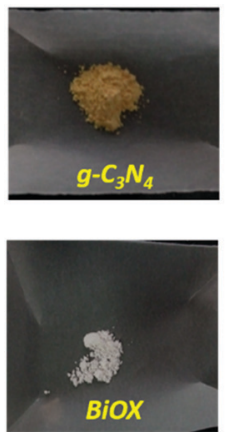

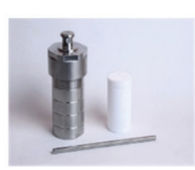

Reaction mixture in hydrothermal reactor

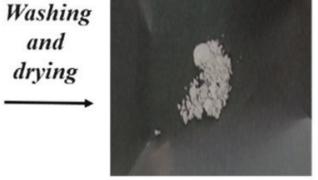

$\mathrm{BiOX}$

$(X=F, C l, B r$ or $I)$
1:1 ratio of $\mathrm{g}-\mathrm{C}_{3} \mathrm{~N}_{4}$ and BiOX sonicated for $1 \mathrm{~h}$

separately, then mixed together and sonicated again for $1 \mathrm{~h}$

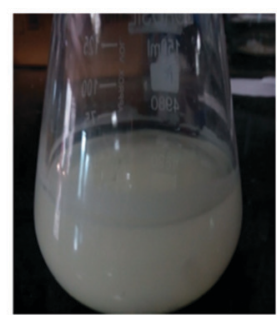

Reaction mixture

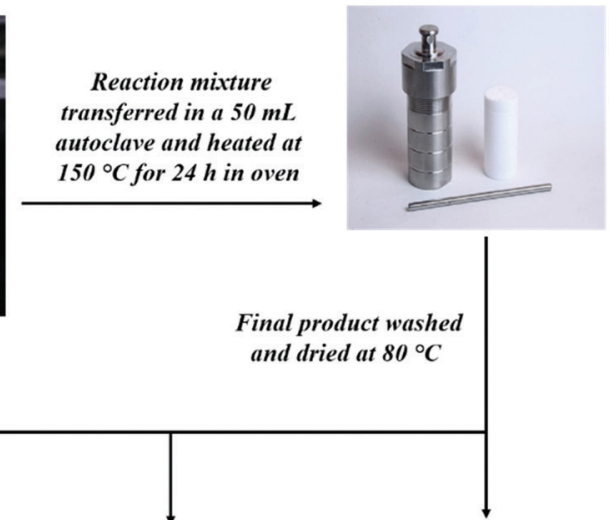

(c)

(d)

(b)
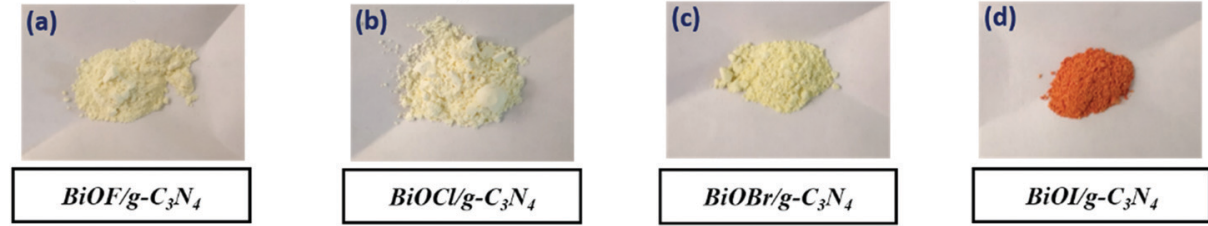

Scheme 2 Schematic representation of the hydrothermal synthesis of BiOX/g- $\mathrm{C}_{3} \mathrm{~N}_{4}$ composites (a) BiOF/g- $\mathrm{C}_{3} \mathrm{~N}_{4}$, (b) BiOCl/g- $\mathrm{C}_{3} \mathrm{~N}_{4}$, (c) BiOBr/g- $\mathrm{C}_{3} \mathrm{~N}_{4}$ and (d) $\mathrm{BiOl} / \mathrm{g}-\mathrm{C}_{3} \mathrm{~N}_{4}$.

of the different BiOX/g- $\mathrm{C}_{3} \mathrm{~N}_{4}$ composites confirm the presence of the constituent components and indicate their successful formation.

\subsection{Morphological, compositional and optical studies}

The morphological analysis of the as prepared samples was carried out using FESEM measurements and the corresponding micrographs are presented in Fig. 3. In this regard, g- $\mathrm{C}_{3} \mathrm{~N}_{4}$ shows an aggregated sheet-like morphology as depicted in Fig. 3a and b. For BiOF, the FESEM image is presented in Fig. 3c, which presents a pentagonal prismatic shape like morphology. On the other hand, BiOCl and BiOBr showed a micron-sized sheet-like morphology with circular and rectangular shapes as presented in Fig. 3d and e, respectively. In the case of BiOI, a flower-like morphology, possibly constructed by aggregation of sheet-like microstructures, has been observed as shown in Fig. 3f. Thus, it can be inferred that, except for BiOF, all other BiOX showed sheet-like morphological characteristics. Furthermore, the FESEM micrographs of the BiOX/g- $\mathrm{C}_{3} \mathrm{~N}_{4}$ composites are depicted in Fig. 4(a-d) with the marked components, which confirms the successful formation of the corresponding composites. In addition, the elemental mapping and EDAX spectrum for a representative composite, $\mathrm{BiOBr} / \mathrm{g}-\mathrm{C}_{3} \mathrm{~N}_{4}$, are presented in Fig. 5, 

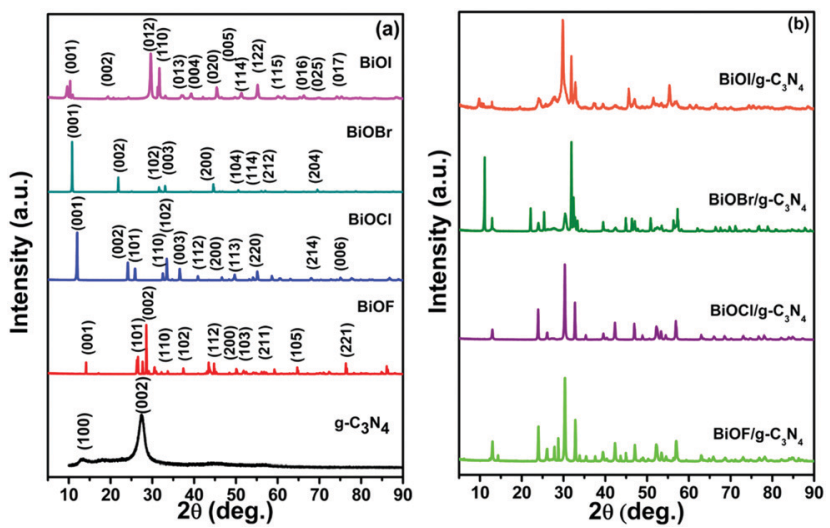

Fig. 1 PXRD pattern of (a) $\mathrm{g}-\mathrm{C}_{3} \mathrm{~N}_{4}, \mathrm{BiOX}(\mathrm{X}=\mathrm{F}, \mathrm{Cl}, \mathrm{Br}$ and I) and (b) BiOX/ g- $\mathrm{C}_{3} \mathrm{~N}_{4}$ composites
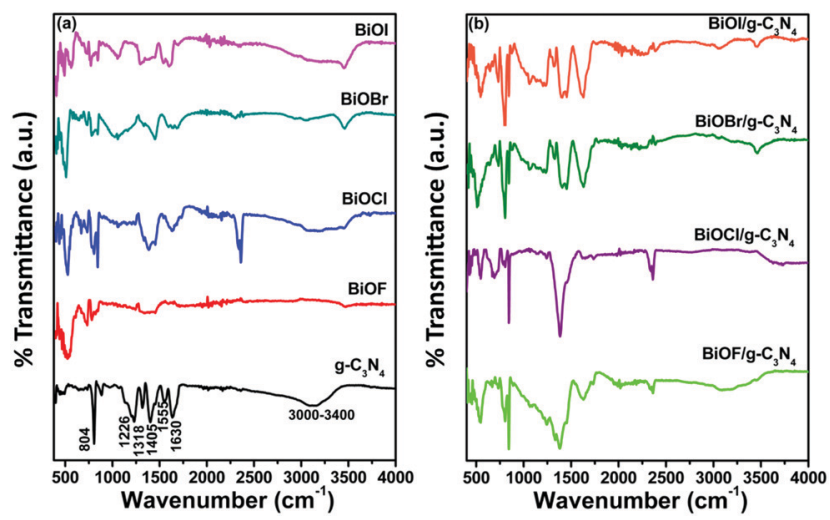

Fig. 2 FTIR spectra of (a) $\mathrm{g}-\mathrm{C}_{3} \mathrm{~N}_{4}, \mathrm{BiOX}(\mathrm{X}=\mathrm{F}, \mathrm{Cl}, \mathrm{Br}$ and I) and (b) $\mathrm{BiOX} /$ g- $\mathrm{C}_{3} \mathrm{~N}_{4}$ composites.
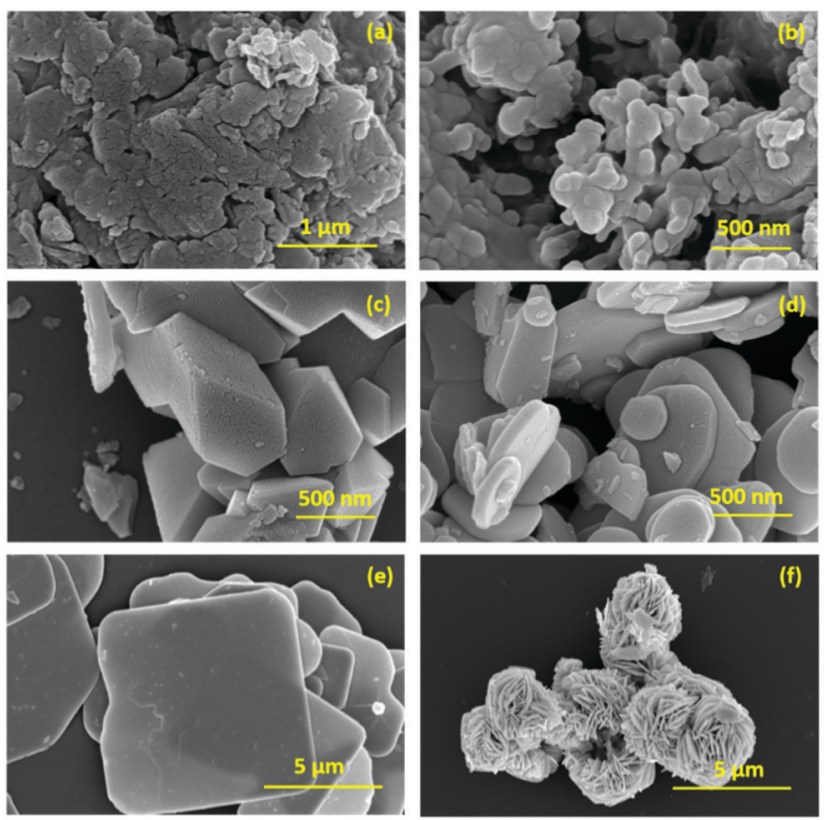

Fig. 3 FESEM images of (a and b) $\mathrm{g}-\mathrm{C}_{3} \mathrm{~N}_{4}$, (c) $\mathrm{BiOF,} \mathrm{(d)} \mathrm{BiOCl}$, (e) $\mathrm{BiOBr}$ and (f) $\mathrm{BiOl}$.

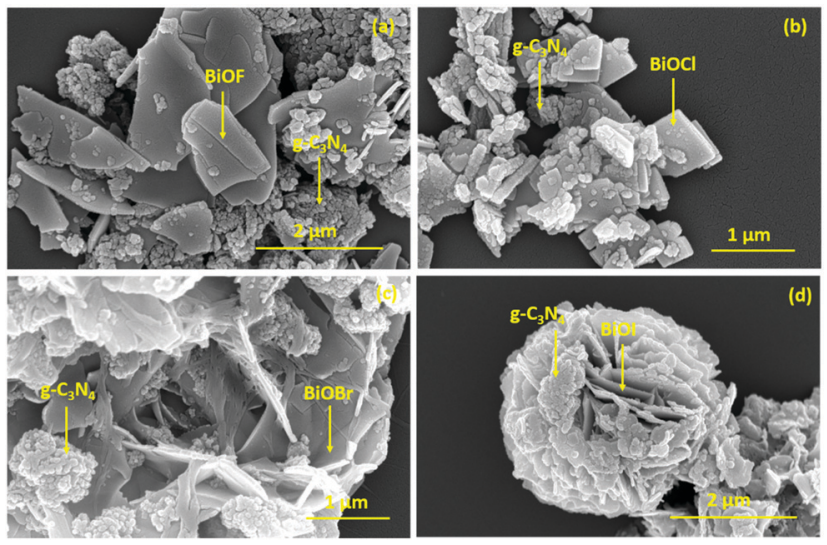

Fig. 4 FESEM images of (a) $\mathrm{BiOF} / \mathrm{g}-\mathrm{C}_{3} \mathrm{~N}_{4}$, (b) $\mathrm{BiOCl} / \mathrm{g}-\mathrm{C}_{3} \mathrm{~N}_{4}$, (c) $\mathrm{BiOBr}$ / g- $\mathrm{C}_{3} \mathrm{~N}_{4}$ and (d) $\mathrm{BiOl} / \mathrm{g}-\mathrm{C}_{3} \mathrm{~N}_{4}$ composites.
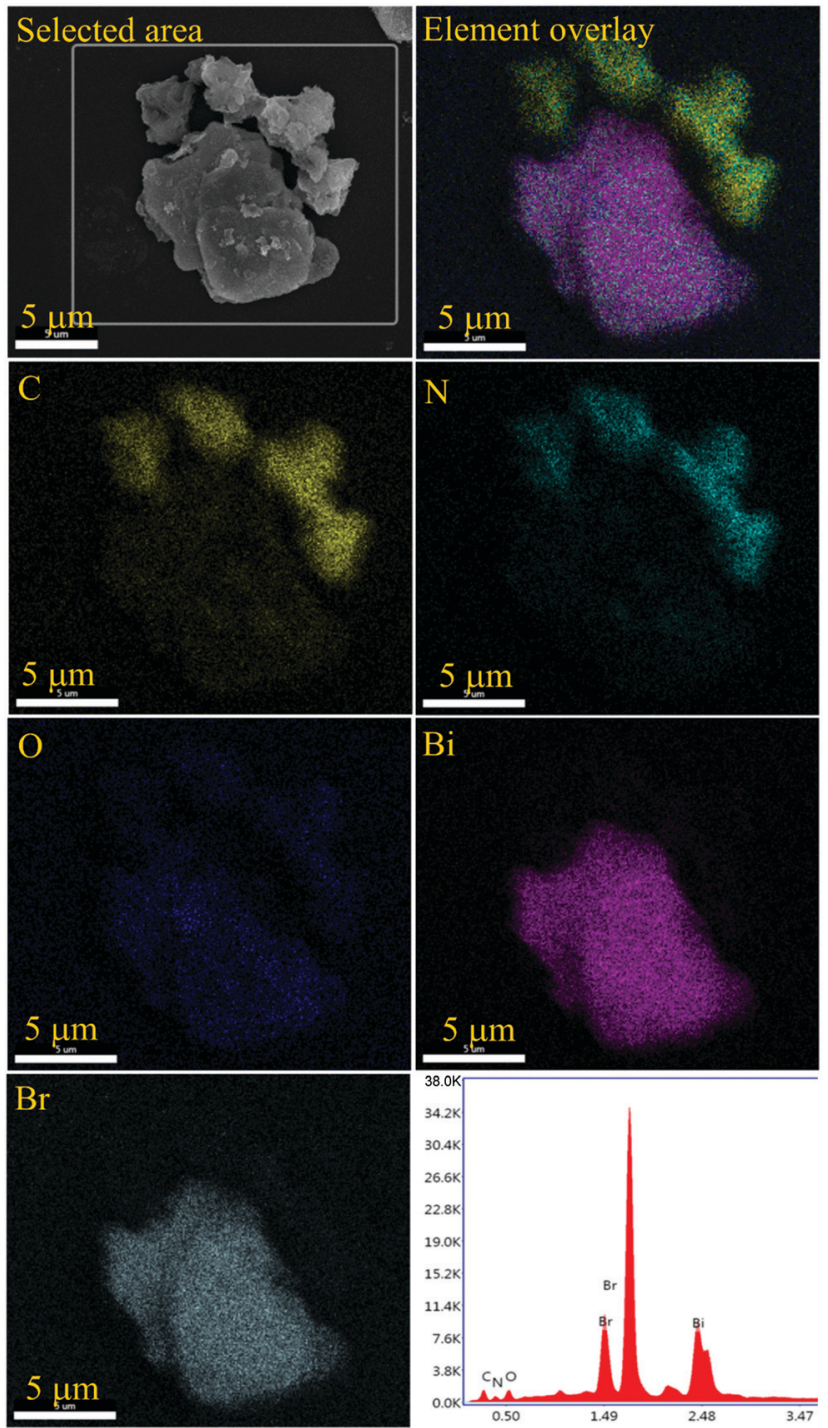

Fig. 5 Elemental mapping and EDAX spectrum of the $\mathrm{BiOBr} / \mathrm{g}-\mathrm{C}_{3} \mathrm{~N}_{4}$ composite.

which confirms the presence and distribution of all the constituent elements. 


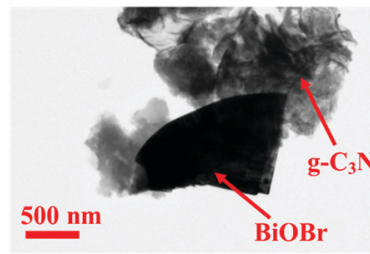

(a)
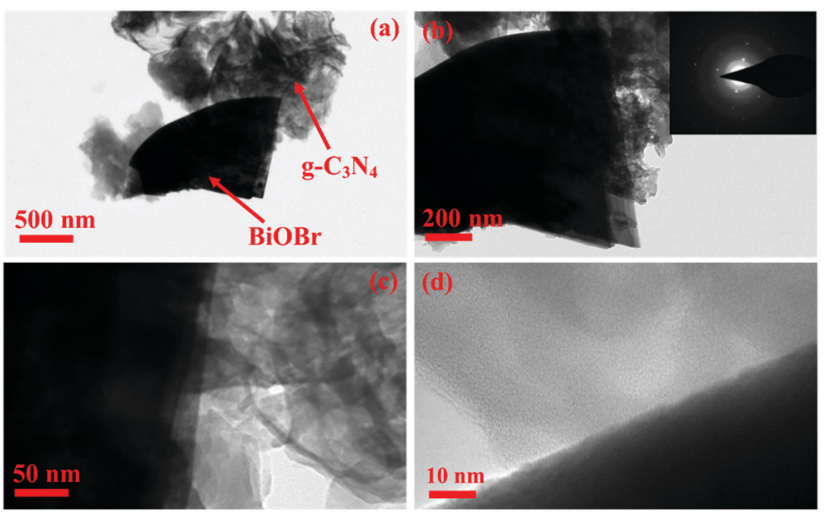

$(\mathrm{e})^{14}-$

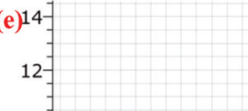

$10-$
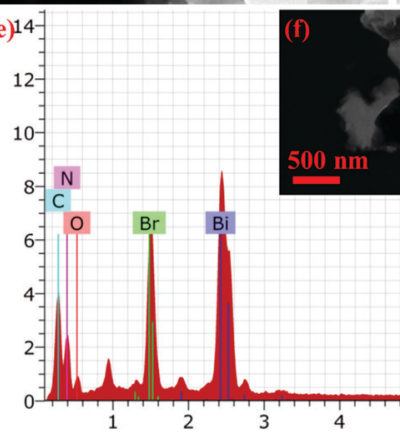

$10 \mathrm{~nm}$

.

.
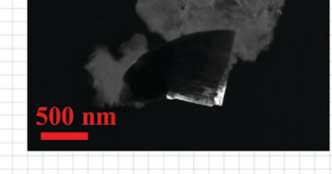
look into the morphology of the $\mathrm{BiOBr} / \mathrm{g}-\mathrm{C}_{3} \mathrm{~N}_{4}$ composite as a representative sample. It can be seen in Fig. 6a that both $\mathrm{BiOBr}$ and $\mathrm{g}-\mathrm{C}_{3} \mathrm{~N}_{4}$ are in close contact with each other, where $\mathrm{BiOBr}$ appears darker due to mass thickness contrast. Fig. $6 \mathrm{~b}$ is the magnified image of Fig. 6a, which shows the presence of both the components, and the diffraction pattern in the inset confirms the single crystalline and amorphous nature of $\mathrm{BiOBr}$ and $\mathrm{g}-\mathrm{C}_{3} \mathrm{~N}_{4}$, respectively. Furthermore, in Fig. $6 \mathrm{c}$ and $\mathrm{d}$, the close interfacial contact between the two components of the $\mathrm{BiOBr} / \mathrm{g}-\mathrm{C}_{3} \mathrm{~N}_{4}$ composite was captured and the lattice fringes were not seen due to the amorphous nature of $g-\mathrm{C}_{3} \mathrm{~N}_{4}$ and high mass thickness contrast of BiOBr. The EDAX data obtained from TEM is presented in Fig. 6e, which shows the presence of the constituent elements in the selected area shown in dark field image Fig. $6 f$.

Further, XPS analysis has been employed for understanding the compositional and electronic properties of the bare $\mathrm{BiOBr}$ and $\mathrm{g}-\mathrm{C}_{3} \mathrm{~N}_{4}$ and a representative composite, $\mathrm{BiOBr} / \mathrm{g}-\mathrm{C}_{3} \mathrm{~N}_{4}$, and the corresponding results are presented in Fig. 7. The survey spectra of these samples confirm the presence of all the constituent elements as presented in Fig. S1 (refer to the ESI $\dagger$ ). The Bi-4f spectra of BiOBr presented in Fig. 7a show two binding energy peaks at 159.5 and $164.8 \mathrm{eV}$, which correspond to the $4 \mathrm{f}_{7 / 2}$ and $4 \mathrm{f}_{5 / 2}$ states of $\mathrm{Bi}$ in $\mathrm{BiOBr}$, respectively, and imply the trivalent state of the element. ${ }^{38,39}$ For the $\mathrm{BiOBr} /$ $\mathrm{g}^{-} \mathrm{C}_{3} \mathrm{~N}_{4}$ composite, the $\mathrm{Bi}-4 \mathrm{f}$ binding energy peaks showed a small shift towards higher binding energy and appear at
159.6 and $165.0 \mathrm{eV} .{ }^{40}$ The high resolution XPS spectrum of C-1s in $\mathrm{g}-\mathrm{C}_{3} \mathrm{~N}_{4}$ is presented in Fig. $7 \mathrm{~b}$, which reveals the existence of carbon in three different environments represented by the three peaks at 285.2, 287.2 and $288.6 \mathrm{eV}$, which belong to graphitic carbon, $\mathrm{C}-\mathrm{N}$ bonds and highly electronegative $\mathrm{C}=\mathrm{N}$ bonds (appears at higher binding energy), respectively. For the $\mathrm{BiOBr} / \mathrm{g}-\mathrm{C}_{3} \mathrm{~N}_{4}$ composite, the binding energy peaks for C-1s appear at 285.2, 286.8 and $288.5 \mathrm{eV}$ with a slight downshift as presented in Fig. 7e. ${ }^{41}$ In Fig. 7c, the XPS spectrum of N-1s of $\mathrm{g}-\mathrm{C}_{3} \mathrm{~N}_{4}$ is shown, which confirms the pyridinic, pyrrolic and graphitic nitrogen peaks at 399.2, 400.2 and $401.1 \mathrm{eV}$, respectively. ${ }^{42}$ For the $\mathrm{BiOBr} / \mathrm{g}-\mathrm{C}_{3} \mathrm{~N}_{4}$ composite, pyridinic and pyrrolic peaks at 399.2 and $400.8 \mathrm{eV}$ with slightly higher binding energies were evidenced as shown in Fig. 7f. The binding energy peaks of $\mathrm{BiOBr}$ for O-1s are depicted in Fig. 7d, which appear at 530.3 and $532.9 \mathrm{eV}$ and can be attributed to lattice oxygen and surface oxygen in $\mathrm{BiOBr}$, whereas these peaks were slightly shifted to 530.3 and $533.0 \mathrm{eV}$ for the BiOBr/g- $\mathrm{C}_{3} \mathrm{~N}_{4}$ composite as shown in Fig. $7 \mathrm{~g} .{ }^{42}$ Similarly, in the case of the Br-3d XPS spectrum of BiOBr (Fig. 7h), the binding energy peaks appear at 68.6 and $69.5 \mathrm{eV}$, which could be associated with energy states $3 \mathrm{~d}_{5 / 2}$ and $3 \mathrm{~d}_{3 / 2}$ in BiOBr. However, in the case of the BiOBr/g- $\mathrm{C}_{3} \mathrm{~N}_{4}$ composite (Fig. 7i), these binding energy peaks got shifted to 69.6 and $68.7 \mathrm{eV}$, respectively. ${ }^{43}$ Therefore, from the XPS study it can be inferred that all prepared samples are composed of the expected constituent elements with high purity and in the desired oxidation states. Also, the slight shifts in the binding energy peaks for the $\mathrm{BiOBr} / \mathrm{g}-\mathrm{C}_{3} \mathrm{~N}_{4}$ composite confirm the significant interaction between the two components, which can help in boosting the charge transfer during the photocatalytic process.

The photocatalytic activity of semiconducting materials is closely related to their band gap, which in turn is related to the optical absorption and emission properties. In this regard, the DRS of all prepared samples were recorded in the wavelength range of 200-800 $\mathrm{nm}$ and corresponding results are presented in Fig. 8a and b. Among all prepared bismuth oxyhalides, BiOI is visible light active and has a narrow band gap of $1.8 \mathrm{eV}$. Also, $\mathrm{g}^{-} \mathrm{C}_{3} \mathrm{~N}_{4}$ possesses a relatively narrow band gap of $2.74 \mathrm{eV}$ and shows absorption in the visible light region of electromagnetic radiation. ${ }^{44}$ All other BiOX, namely $\mathrm{BiOF}, \mathrm{BiOCl}$ and $\mathrm{BiOBr}$, are UV light active and have band gaps of 3.52, 3.45, 3.10 and $1.80 \mathrm{eV}$, respectively, as determined from the transformed Kubelka-Munk plot shown in Fig. S2 (refer to the ESI $\dagger$ ). The band gap values determined for the different BiOX are in good agreement with previously reported data. ${ }^{25}$ Also, it can be seen from the DRS plots of different composites that the formation of BiOX/g- $\mathrm{C}_{3} \mathrm{~N}_{4}$ leads to a change in the optical properties, wherein an enhancement leading to better UV-vis light absorption can be seen, which could significantly improve their photocatalytic activity. In addition, the BET surface area was also measured for $\mathrm{g}-\mathrm{C}_{3} \mathrm{~N}_{4}$ and representative samples $\mathrm{BiOBr}$ and the $\mathrm{BiOBr} / \mathrm{g}-\mathrm{C}_{3} \mathrm{~N}_{4}$ composite. $\mathrm{g}-\mathrm{C}_{3} \mathrm{~N}_{4}$ exhibited the highest surface area of $12.35 \mathrm{~m}^{2} \mathrm{~g}^{-1}$ among these samples due to its sheet-like morphology. The BiOBr sample possesses a bulk thick sheet-like morphology and therefore its surface area $\left(1.54 \mathrm{~m}^{2} \mathrm{~g}^{-1}\right)$ was found to be lower. For the $\mathrm{BiOBr} /$ $\mathrm{g}-\mathrm{C}_{3} \mathrm{~N}_{4}$ composite, a moderate area of $3.81 \mathrm{~m}^{2} \mathrm{~g}^{-1}$ was observed. 

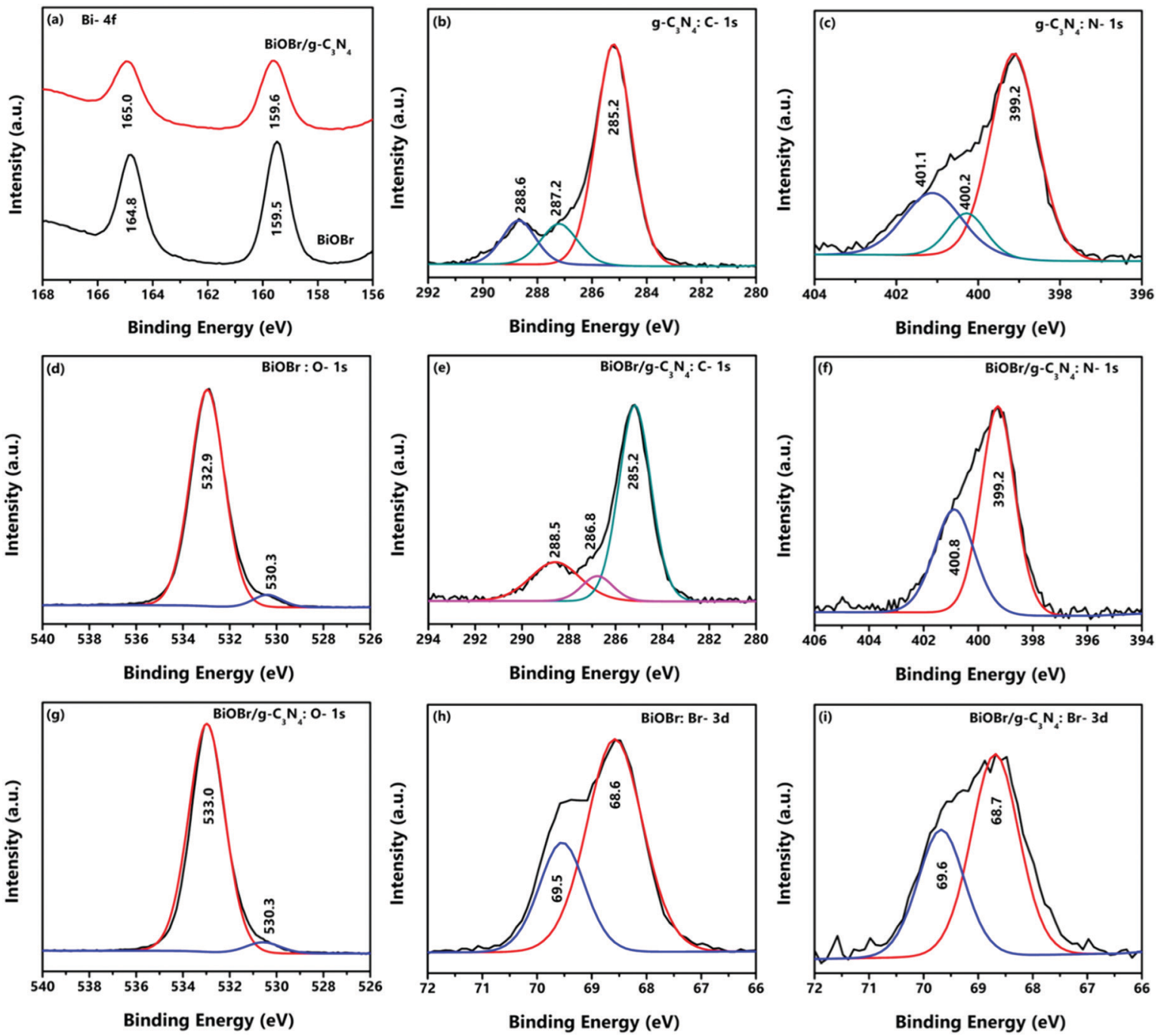

Fig. 7 High resolution XPS spectra of $\mathrm{g}-\mathrm{C}_{3} \mathrm{~N}_{4}, \mathrm{BiOBr}$ and the $\mathrm{BiOBr} / \mathrm{g}-\mathrm{C}_{3} \mathrm{~N}_{4}$ composite
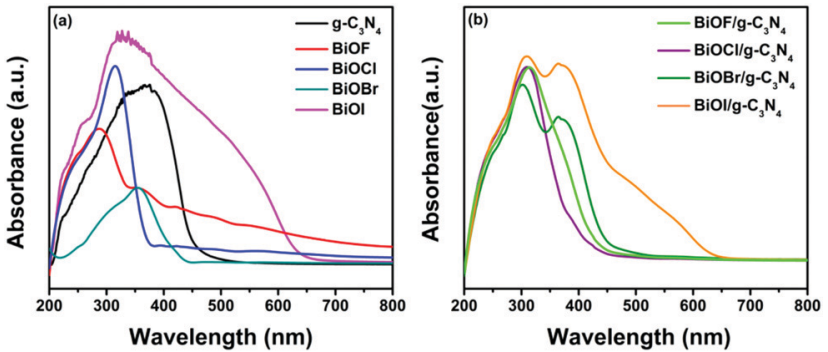

Fig. 8 DRS plots of (a) BiOX and g- $\mathrm{C}_{3} \mathrm{~N}_{4}$ and (b) BiOX/g- $\mathrm{C}_{3} \mathrm{~N}_{4}$ composites $(\mathrm{X}=\mathrm{F}, \mathrm{Cl}, \mathrm{Br}$ and $\mathrm{I})$.

\subsection{Photocatalytic activity studies}

The photocatalytic activity of the materials $\mathrm{g}-\mathrm{C}_{3} \mathrm{~N}_{4}, \mathrm{BiOX}$ and BiOX/g- $\mathrm{C}_{3} \mathrm{~N}_{4}$ composites was investigated by monitoring the photo-degradation of a model pollutant, CR dye, under natural sunlight irradiation and the obtained results are shown as histograms in Fig. 8. The decrease in the prominent absorption peak of CR dye at $496 \mathrm{~nm}$ was observed using UV-vis spectroscopy to quantify the amount of dye degraded in each experiment, which was carried out for $90 \mathrm{~min}$. The time dependent UV-vis spectra of the degradation of the dye by bare catalysts and all composites are provided in Fig. S3 and S4, respectively (refer to the ESI $\dagger$ ). The rate of degradation, which is a measure of the photocatalytic activity, was significantly higher in the case of the BiOX/g- $\mathrm{C}_{3} \mathrm{~N}_{4}$ composites than the bare catalysts, while the amount of degradation was almost negligible without any catalyst (photolysis case). It can be seen from Fig. 9a that pristine g- $\mathrm{C}_{3} \mathrm{~N}_{4}$ showed about $63 \%$ CR degradation after 90 min irradiation under natural sunlight. Among the different bismuth oxyhalides, BiOBr showed maximum degradation of around $70 \%$, which is also higher than the pristine $\mathrm{g}-\mathrm{C}_{3} \mathrm{~N}_{4}$ in the same time period. The minimum photocatalytic performance was observed in the case of BiOF, which could be attributed to its highest band gap and more prominent charge recombination. On the other hand, upon the formation of the BiOX/g- $\mathrm{C}_{3} \mathrm{~N}_{4}$ composites, a significant enhancement in the photocatalytic performance could be observed as depicted in Fig. 9b. Among the composites, BiOBr/g- $\mathrm{C}_{3} \mathrm{~N}_{4}$ showed the maximum degradation of around $92 \%$ followed by $\mathrm{BiOCl} / \mathrm{g}-\mathrm{C}_{3} \mathrm{~N}_{4}(90 \%), \mathrm{BiOF} / \mathrm{g}-\mathrm{C}_{3} \mathrm{~N}_{4}(84 \%)$ and $\mathrm{BiOI} / \mathrm{g}-\mathrm{C}_{3} \mathrm{~N}_{4}(79 \%)$ in 

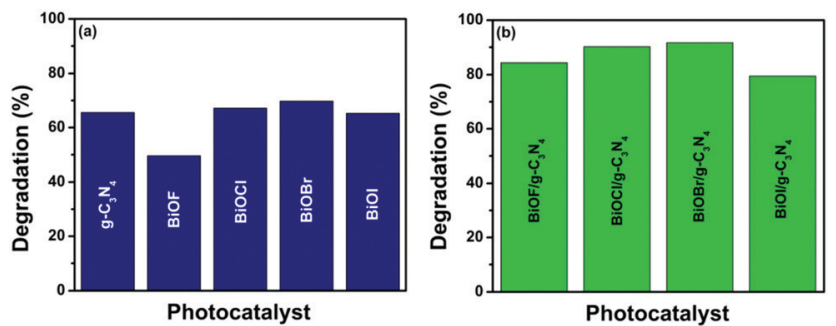

Fig. 9 Photocatalytic activity plots presenting the percentage of degradation of $\mathrm{CR}$ dye under sunlight irradiation for a stipulated time of 90 min using (a) bare BiOX and $\mathrm{g}-\mathrm{C}_{3} \mathrm{~N}_{4}$ as catalysts and (b) different BiOX/g- $\mathrm{C}_{3} \mathrm{~N}_{4}$ composites as catalysts.

the same time period. Hence, it can be inferred that the BiOBr/ g- $\mathrm{C}_{3} \mathrm{~N}_{4}$ composite has shown the best photocatalytic performance among all prepared samples towards the degradation of CR dye. The better generation, separation and transfer of photo-induced electrons and holes in the case of the $\mathrm{BiOBr} / \mathrm{g}-\mathrm{C}_{3} \mathrm{~N}_{4}$ composite can be ascribed to its enhanced photocatalytic activity, which ultimately leads to the high pollutant degradation efficiency.

In addition, the kinetics of photocatalytic degradation of $\mathrm{CR}$ dye was also studied by applying the pseudo first-order reaction model to the obtained spectral data by using the following integral equation: ${ }^{45}$

$$
\ln \left(C / C_{0}\right)=-k t
$$

In this equation, $C_{0}$ is the concentration of CR dye at time $t=0$, $C$ is the concentration at time $t=t$ and $k$ is the rate constant of the photocatalytic reaction. Kinetic plots for the degradation of CR dye with different photocatalysts are presented in Fig. 10. It can be seen from Fig. 10 that the degradation of CR dye follows pseudo first-order reaction kinetics and corresponding parameters (rate constant, half-life time and $R^{2}$-values) are presented in Table S1 (refer to the ESI $\dagger$ ). The rate constant
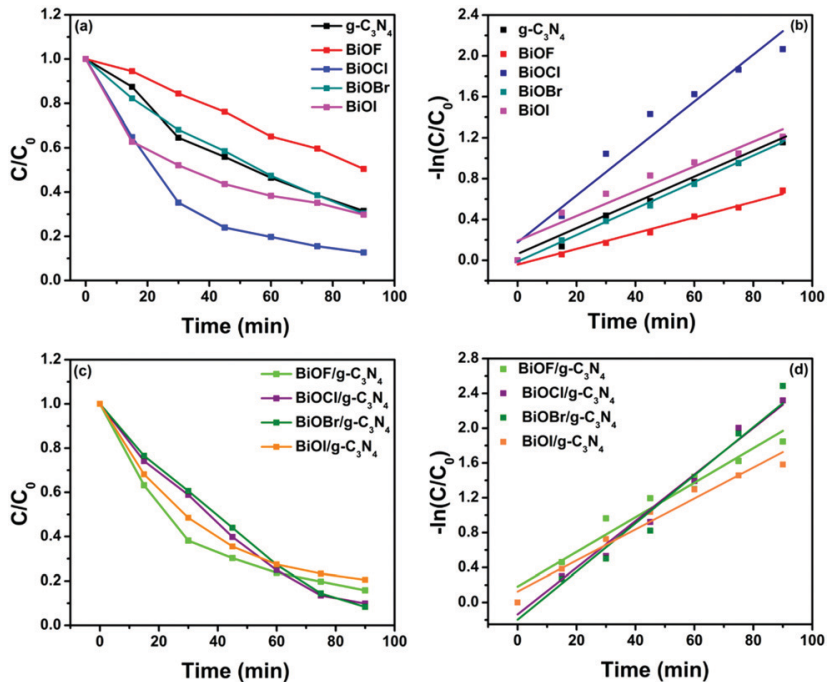

Fig. 10 Kinetic curves obtained by applying a pseudo first order kinetic model for the photo-degradation of CR dye using ( $a$ and b) different bare BiOX and $\mathrm{g}-\mathrm{C}_{3} \mathrm{~N}_{4}$ and (c and d) different BiOX/g- $\mathrm{C}_{3} \mathrm{~N}_{4}$ composites. for the different composites follows the order: BiOBr $/ \mathrm{g}-\mathrm{C}_{3} \mathrm{~N}_{4}$ $\left(0.028 \mathrm{~min}^{-1}\right)>\mathrm{BiOCl} / \mathrm{g}-\mathrm{C}_{3} \mathrm{~N}_{4}\left(0.027 \mathrm{~min}^{-1}\right)>\mathrm{BiOF} / \mathrm{g}-\mathrm{C}_{3} \mathrm{~N}_{4}$ $\left(0.020 \mathrm{~min}^{-1}\right)>\mathrm{BiOBr} / \mathrm{g}-\mathrm{C}_{3} \mathrm{~N}_{4}\left(0.018 \mathrm{~min}^{-1}\right)$. The highest rate constant value of $0.028 \mathrm{~min}^{-1}$ for the $\mathrm{BiOBr} / \mathrm{g}-\mathrm{C}_{3} \mathrm{~N}_{4}$ composite confirms its superior photocatalytic performance towards CR degradation in comparison to the other bare and composite photocatalysts. To validate the true photocatalytic activity of the BiOX $/ \mathrm{g}-\mathrm{C}_{3} \mathrm{~N}_{4}$ composites, the best composite, BiOBr $/ \mathrm{g}-\mathrm{C}_{3} \mathrm{~N}_{4}$, was chosen for investigating the degradation of a colorless fungicide, carbendazim (CBZ), under identical conditions. The obtained results in terms of the degradation profile of CBZ are provided in Fig. S5 (refer to the ESI $\dagger$ ). It has been found that BiOBr/g- $\mathrm{C}_{3} \mathrm{~N}_{4}$ composite photocatalyst degrades $52 \%$ of colorless CBZ in $90 \mathrm{~min}$, which confirms that this composite possesses true photocatalytic activity by degrading a colorless pollutant. The photocatalytic degradation performance of the best catalyst is also compared with other carbon nitride based photocatalysts in Table 1, which indicates that this photocatalyst shows appreciable activity.

Furthermore, the stability and reusability of the photocatalyst are important in heterogeneous catalysis. In this regard, the stability and reusability of the photocatalyst were studied using the best composite, i.e. $\mathrm{BiOBr} / \mathrm{g}-\mathrm{C}_{3} \mathrm{~N}_{4}$, for three cycles of CR dye degradation. After each cycle completion, the catalyst was recovered by centrifugation and before using it in the next cycles it was washed with deionized water and dried. The result of the photocatalytic activity for three cycles is shown in Fig. 11a, which indicates that there was no significant decrease in the photocatalytic activity between consecutive cycles. The stability of the $\mathrm{BiOBr} / \mathrm{g}-\mathrm{C}_{3} \mathrm{~N}_{4}$ composite after three cycles of photocatalytic reaction has been confirmed by measuring PXRD data. As shown in Fig. 11b, the PXRD pattern of the composite recovered after three cycles matches well with the pattern of the fresh composite, illustrating that the photocatalyst possesses excellent stability and recyclability properties. In addition, the FTIR spectra of the fresh and recycled BiOBr/g- $\mathrm{C}_{3} \mathrm{~N}_{4}$ composite were also measured (Fig. S6, ESI + ), which showed that the characteristic peaks of both the components were preserved after three cycles of photodegradation of CR dye.

\subsection{Mechanism of photocatalytic activity}

The comparison of the percentage of CR dye degradation shown by each photocatalyst reveals that the BiOX/g- $\mathrm{C}_{3} \mathrm{~N}_{4}$ composites exhibit higher photocatalytic performance in comparison to the bare components. Among the composites, $\mathrm{BiOBr} / \mathrm{g}-\mathrm{C}_{3} \mathrm{~N}_{4}$ showed maximum degradation of $\mathrm{CR}$, which could be attributed to efficient charge separation and transfer through the binary interface. To prove this, PL studies were carried out for bare BiOBr and $\mathrm{g}-\mathrm{C}_{3} \mathrm{~N}_{4}$ and the $\mathrm{BiOBr} / \mathrm{g}-\mathrm{C}_{3} \mathrm{~N}_{4}$ composite to study the generation and separation of photogenerated electron-hole pairs in the photocatalysts. According to the photoluminescence study, the intensity of a PL spectrum increases as the charge recombination of electron-hole pairs increases and vice versa ${ }^{53,54}$ The PL spectra of bare $\mathrm{BiOBr}$ and g- $\mathrm{C}_{3} \mathrm{~N}_{4}$ and the $\mathrm{BiOBr} / \mathrm{g}-\mathrm{C}_{3} \mathrm{~N}_{4}$ composite are shown in Fig. 12a. As can be seen, the PL spectrum of the BiOBr/ $\mathrm{g}^{-} \mathrm{C}_{3} \mathrm{~N}_{4}$ composite is less intense in comparison to its bare counterparts. This indicates that the charge recombination in the case of $\mathrm{g}-\mathrm{C}_{3} \mathrm{~N}_{4}$ and $\mathrm{BiOBr}$ is quite high, which limits their 
Table 1 Comparison of the photocatalytic activity of the $\mathrm{BiOBr} / \mathrm{g}-\mathrm{C}_{3} \mathrm{~N}_{4}$ composite with several other carbon nitride based photocatalysts

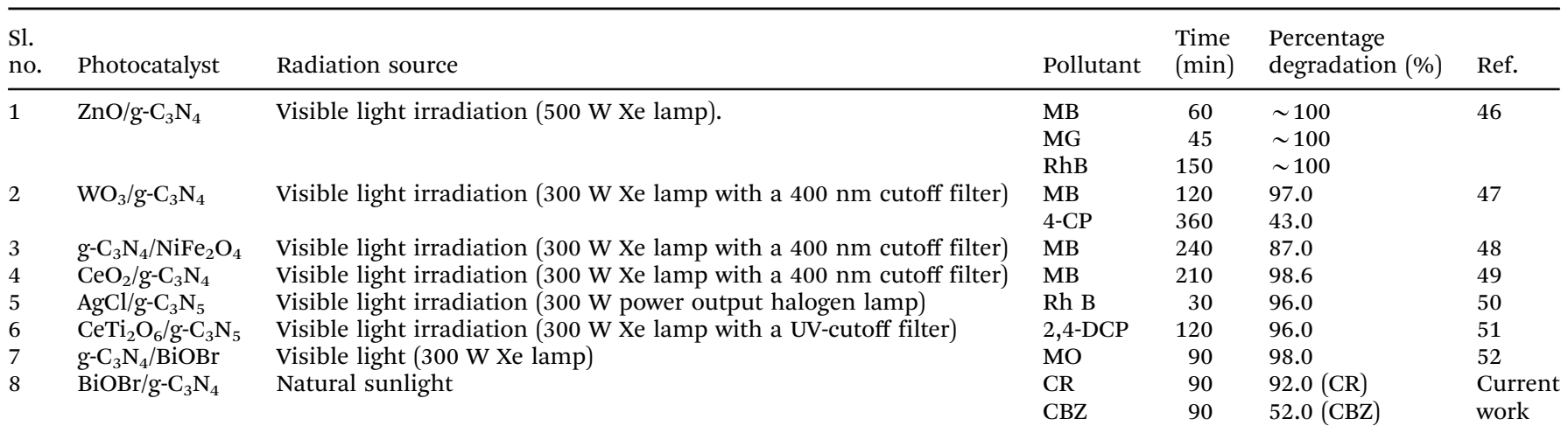

Methyl orange (MO), methylene blue (MB), malachite green (MG), rhodamine B (Rh B), 4-chlorophenol (4-CP), 2,4-dichlorophenol (2,4-DCP), Congo red (CR) and carbendazim (CBZ).
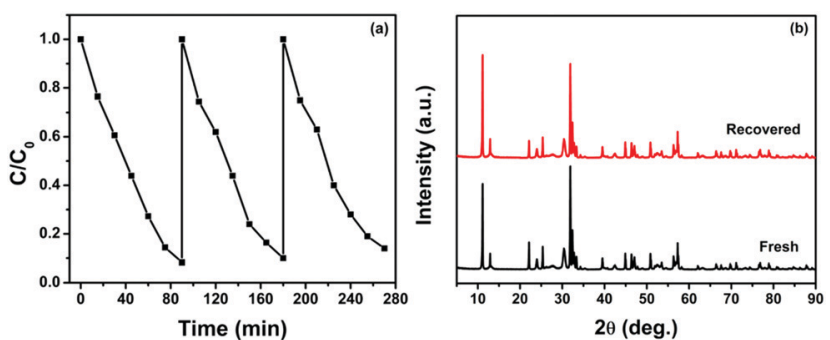

Fig. 11 (a) Photocatalytic activity of the $\mathrm{BiOBr} / \mathrm{g}-\mathrm{C}_{3} \mathrm{~N}_{4}$ composite towards $\mathrm{CR}$ dye degradation for three cycles and (b) PXRD patterns of fresh and recovered catalysts.
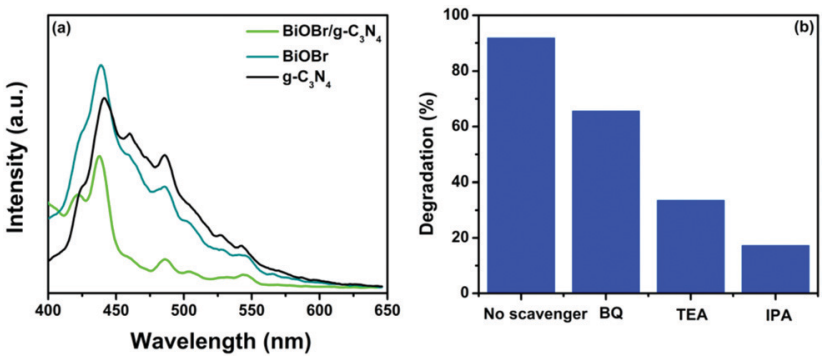

Fig. 12 (a) PL spectra of $\mathrm{g}-\mathrm{C}_{3} \mathrm{~N}_{4}, \mathrm{BiOBr}$ and the $\mathrm{BiOBr} / \mathrm{g}-\mathrm{C}_{3} \mathrm{~N}_{4}$ composite and (b) effect of scavengers on the photocatalytic activity of the $\mathrm{BiOBr} /$ g- $\mathrm{C}_{3} \mathrm{~N}_{4}$ composite towards $\mathrm{CR}$ degradation under sunlight irradiation.

photocatalytic activity. However, after the formation of the BiOBr/ g- $\mathrm{C}_{3} \mathrm{~N}_{4}$ composite, the charge recombination between photoinduced electrons and holes markedly decreases, which can help enhance the photocatalytic activity. To further understand the charge transfer mechanism, the calculation of the band edge potentials of $\mathrm{BiOBr}$ and $g-\mathrm{C}_{3} \mathrm{~N}_{4}$ has been carried out by using the following equations: ${ }^{55}$

$$
\begin{gathered}
E_{\mathrm{CB}}=\chi-E_{\mathrm{e}}-0.5 E_{\mathrm{g}} \\
E_{\mathrm{VB}}=E_{\mathrm{CB}}+E_{\mathrm{g}}
\end{gathered}
$$

Here $E_{\mathrm{VB}}$ and $E_{\mathrm{CB}}$ are the valence band (VB) and conduction band (CB) edge potentials, respectively, and $E_{\mathrm{g}}$ is the band gap of the semiconductor material. The band gaps of BiOBr and $\mathrm{g}^{-} \mathrm{C}_{3} \mathrm{~N}_{4}$ are 3.10 and $2.74 \mathrm{eV}$, respectively (as determined from DRS study), and $\chi$ is the Sanderson electronegativity, which is equal to 4.64 and $6.18 \mathrm{eV}$ for $\mathrm{g}-\mathrm{C}_{3} \mathrm{~N}_{4}$ and $\mathrm{BiOBr}$, respectively. ${ }^{56,57} E_{\mathrm{e}}$ is the energy of a free electron on the hydrogen scale, i.e. $4.5 \mathrm{eV} v$ s. NHE. Substituting all values into the above equation, the calculated $\mathrm{VB}$ and $\mathrm{CB}$ edge positions of $\mathrm{g}-\mathrm{C}_{3} \mathrm{~N}_{4}$ were found at 1.51 and $-1.23 \mathrm{eV} v$ s. NHE, respectively. Similarly, the VB and CB edge positions of BiOBr lie at 3.23 and $0.13 \mathrm{eV} v s$. NHE, respectively. Based on this, a plausible mechanism of CR degradation under sunlight irradiation is depicted in Scheme 3. It has been well established that bare $\mathrm{g}-\mathrm{C}_{3} \mathrm{~N}_{4}$ and BiOBr show absorption in the visible region and UV region, respectively, of the solar spectrum. The successful composite formation of BiOBr over $\mathrm{g}-\mathrm{C}_{3} \mathrm{~N}_{4}$ results in a synergistic effect, which allows simultaneous absorption in both the UV and visible regions of light. Also, the appropriate band positions of each component in the $\mathrm{BiOBr} / \mathrm{g}-\mathrm{C}_{3} \mathrm{~N}_{4}$ composite allow efficient charge transfer through the formed interfaces and suppress the recombination of photogenerated charges, which ultimately boosts the photocatalytic performance. Based on the thermodynamic feasibility of charge transfer, downward electron transfer from the $\mathrm{CB}$ of $\mathrm{g}-\mathrm{C}_{3} \mathrm{~N}_{4}$ to the $\mathrm{CB}$ of BiOBr takes place, whereas holes move upward from the $\mathrm{VB}$ of $\mathrm{BiOBr}$ to the $\mathrm{VB}$ of $\mathrm{g}-\mathrm{C}_{3} \mathrm{~N}_{4}{ }^{58}$ Since the $\mathrm{CB}$ of $\mathrm{BiOBr}$ is more positive than the reduction potential

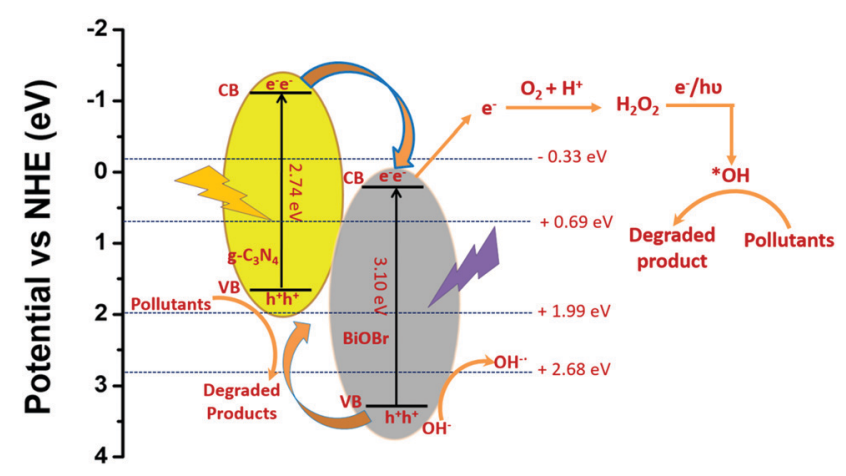

Scheme 3 Plausible mechanism of degradation of $\mathrm{CR}$ under sunlight irradiation over the $\mathrm{BiOBr} / \mathrm{g}-\mathrm{C}_{3} \mathrm{~N}_{4}$ composite. 
of $\mathrm{O}_{2} / \mathrm{O}_{2}{ }^{-*}$ conversion $(-0.33 \mathrm{eV})$, the formation of $\mathrm{O}_{2}{ }^{-*}$ does not take place. The photoexcited electrons transferred to the $\mathrm{CB}$ of $\mathrm{BiOBr}$ react with the oxygen present on the surface of the photocatalytic material and form $\mathrm{H}_{2} \mathrm{O}_{2}$ as the reduction potential value of $\mathrm{O}_{2} / \mathrm{H}_{2} \mathrm{O}_{2}$ is more positive $(+0.69 \mathrm{eV} v s$. NHE) with respect to the $\mathrm{CB}$ of $\mathrm{BiOBr}\left(+0.13 \mathrm{eV}\right.$ vs. NHE) ${ }^{59}$ The holes in the $\mathrm{VB}$ of $\mathrm{g}-\mathrm{C}_{3} \mathrm{~N}_{4}$ react directly with the pollutant molecules due to their lower reduction potential to generate $\mathrm{OH}^{*}$ radicals $\left(\mathrm{OH}^{-} /{ }^{*} \mathrm{OH}=\right.$ $1.99 \mathrm{eV} v s$. NHE). On the other hand, the holes in the VB of $\mathrm{BiOBr}$ react with water molecules, which forms $\mathrm{OH}^{*}$ radicals $\left({ }^{*} \mathrm{OH} / \mathrm{H}_{2} \mathrm{O}=2.68 \mathrm{eV} v s\right.$. NHE), and more of these radicals get generated in the presence of sunlight by decomposition of $\mathrm{H}_{2} \mathrm{O}_{2} \cdot{ }^{60}$ Therefore, $\mathrm{OH}^{*}$ radicals act as highly reactive oxidizing species and oxidize the toxic organic pollutant molecules into simpler non-toxic molecules, like $\mathrm{H}_{2} \mathrm{O}$ and $\mathrm{CO}_{2}$. Based on this, the degradation reaction mechanism can be formulated as:

$$
\begin{gathered}
\text { g- } \mathrm{C}_{3} \mathrm{~N}_{4}\left(\mathrm{e}^{-} \mathrm{CB}\right) \rightarrow \operatorname{BiOBr}\left(\mathrm{e}^{-} \mathrm{CB}\right) \\
\operatorname{BiOBr}\left(\mathrm{e}^{-}\right)+\mathrm{H}^{+}+\mathrm{O}_{2} \rightarrow \mathrm{H}_{2} \mathrm{O}_{2} \\
\mathrm{H}_{2} \mathrm{O}_{2}+\mathrm{e}^{-}+h \nu \rightarrow \mathrm{OH}^{*}+\mathrm{OH}^{-} \\
\mathrm{VB}\left(\mathrm{h}^{+}\right)+\mathrm{H}_{2} \mathrm{O} \rightarrow \mathrm{H}^{+}+\mathrm{OH}^{*} \\
\mathrm{OH}^{*}+\text { pollutant molecules } \rightarrow \text { degraded products }
\end{gathered}
$$

To validate the proposed mechanism and to investigate the role of reactive oxygen species in the degradation process, a scavenger study was carried out using different scavengers, viz. benzoquinone (BQ), isopropyl alcohol (IPA) and triethanolamine (TEA), for the degradation of CR dye. BQ, TEA and IPA act as scavengers for $\mathrm{O}_{2}{ }^{-*}, \mathrm{~h}^{+}$, and $\mathrm{OH}^{*}$ reactive species, respectively. ${ }^{7}$ The results of the scavenger study are depicted in Fig. 12b, which shows minimum degradation in the presence of IPA (18\%), followed by TEA (33\%), and much less effect in the degradation percentage with BQ (66\%). These trapping experiment results reveal that $\mathrm{OH}^{*}$ and $\mathrm{h}^{+}$are the main reactive species involved in the degradation of $\mathrm{CR}$ dye and the $\mathrm{O}_{2}{ }^{-*}$ species has negligible effect. The rate of formation of these reactive species is high in composites $\mathrm{BiOBr} / \mathrm{g}-\mathrm{C}_{3} \mathrm{~N}_{4}$ compared to bare photocatalyst $\mathrm{BiOBr}$ and $\mathrm{g}-\mathrm{C}_{3} \mathrm{~N}_{4}$ as a result of suppressed charge recombination, because of which the composite shows high photocatalytic activity under sunlight irradiation for organic pollutant degradation.

\section{Conclusion}

In this comparative study, we have synthesized four different BiOX/g- $\mathrm{C}_{3} \mathrm{~N}_{4}$ composites by using a $1: 1$ ratio of bare catalyst BiOX and $\mathrm{g}-\mathrm{C}_{3} \mathrm{~N}_{4}$ by a hydrothermal synthesis route. The photocatalytic activity of the composites and the bare catalysts was studied by monitoring the degradation of aqueous solutions of a colored dye (CR) and a colorless fungicide (CBZ) under sunlight irradiation. The appropriate band edge potential and better interfacial contact between $\mathrm{BiOX}$ and $\mathrm{g}-\mathrm{C}_{3} \mathrm{~N}_{4}$ have contributed to the increase in the photocatalytic activity of the composites in comparison to the bare BiOX and $\mathrm{g}-\mathrm{C}_{3} \mathrm{~N}_{4}$ catalysts. The high rate of formation of photoexcited electron-hole pairs with suppressed charge carrier recombination has given rise to excellent photocatalytic activity of composite BiOX/g- $\mathrm{C}_{3} \mathrm{~N}_{4}$ over bare BiOX and g- $\mathrm{C}_{3} \mathrm{~N}_{4}$ toward pollutant degradation. Among the different BiOX/g- $\mathrm{C}_{3} \mathrm{~N}_{4}$ composites, $\mathrm{BiOBr} / \mathrm{g}-\mathrm{C}_{3} \mathrm{~N}_{4}$ shows superior photocatalytic activity to the other BiOX/g- $\mathrm{C}_{3} \mathrm{~N}_{4}$ composites due to the favorable band edge potentials between the UV light active $\mathrm{BiOBr}$ and visible light active $\mathrm{g}-\mathrm{C}_{3} \mathrm{~N}_{4}$ materials. The active species trapping experiments revealed that the $\mathrm{OH}^{*}$ radical was the main reactive species, which plays a major role in the degradation of the pollutants. Hence, the composite formation of BiOX with $\mathrm{g}-\mathrm{C}_{3} \mathrm{~N}_{4}$ provides new insight on bismuth oxyhalides and $\mathrm{g}-\mathrm{C}_{3} \mathrm{~N}_{4}$ based photocatalysts for organic pollutant degradation. Moreover, similar photocatalytic systems can also be synthesized and utilized for other photocatalytic applications for energy conversion and organic transformation reactions, in addition to environmental remediation applications.

\section{Conflicts of interest}

There are no conflicts to declare.

\section{Acknowledgements}

We are thankful to Advanced Materials Research Centre (AMRC), IIT Mandi, for synthesis and the characterization facilities. Ashish Kumar gratefully acknowledges Council of Scientific Industrial Research (CSIR), New Delhi, India, for financial support through a senior research fellowship.

\section{Notes and references}

1 T. Wang, C. Nie, Z. Ao, S. Wang and T. An, J. Mater. Chem. A, 2020, 8, 485-502.

2 S. Kumar, A. Kumar, A. Kumar and V. Krishnan, Catal. Rev., 2019, 1-60.

3 A. Kumar, S. Kumar, A. Bahuguna, A. Kumar, V. Sharma and V. Krishnan, Mater. Chem. Front., 2017, 1, 2391-2404.

4 M. Wen, G. Li, H. Liu, J. Chen, T. An and H. Yamashita, Environ. Sci.: Nano, 2019, 6, 1006-1025.

5 K. Lingeshwar Reddy, R. Balaji, A. Kumar and V. Krishnan, Small, 2018, 14, 1801304.

6 A. Kumar, S. Kumar and V. Krishnan, Nanophotocatalysis and Environmental Applications, Springer, 2019, pp. 139-165.

7 A. Kumar, V. Navakoteswara Rao, A. Kumar, M. Venkatakrishnan Shankar and V. Krishnan, ChemPhotoChem, 2020, 4, 427-444.

8 J. Wen, J. Xie, X. Chen and X. Li, Appl. Surf. Sci., 2017, 391, 72-123.

9 F. K. Kessler, Y. Zheng, D. Schwarz, C. Merschjann, W. Schnick, X. Wang and M. J. Bojdys, Nat. Rev. Mater., 2017, 2, 1-17.

10 W.-J. Ong, L.-L. Tan, Y. H. Ng, S.-T. Yong and S.-P. Chai, Chem. Rev., 2016, 116, 7159-7329. 
11 J. Hong, X. Xia, Y. Wang and R. Xu, J. Mater. Chem., 2012, 22, 15006-15012.

12 Y. Zhang, Z. Schnepp, J. Cao, S. Ouyang, Y. Li, J. Ye and S. Liu, Sci. Rep., 2013, 3, 2163.

13 S. Tonda, S. Kumar, S. Kandula and V. Shanker, J. Mater. Chem. A, 2014, 2, 6772-6780.

14 Y. Zeng, X. Liu, C. Liu, L. Wang, Y. Xia, S. Zhang, S. Luo and Y. Pei, Appl. Catal., B, 2018, 224, 1-9.

15 S. Kumar, A. Kumar, A. Bahuguna, V. Sharma and V. Krishnan, Beilstein J. Nanotechnol., 2017, 8, 1571-1600.

16 L. Shi, W. Ding, S. Yang, Z. He and S. Liu, J. Hazard. Mater., 2018, 347, 431-441.

17 R. Ma, S. Zhang, L. Li, P. Gu, T. Wen, A. Khan, S. Li, B. Li, S. Wang and X. Wang, ACS Sustainable Chem. Eng., 2019, 7, 9699-9708.

18 A. Kumar, C. Schuerings, S. Kumar, A. Kumar and V. Krishnan, Beilstein J. Nanotechnol., 2018, 9, 671-685.

19 S. Kumar, A. Kumar, A. Kumar, R. Balaji and V. Krishnan, ChemistrySelect, 2018, 3, 1919-1932.

20 L. Ma, G. Wang, C. Jiang, H. Bao and Q. Xu, Appl. Surf. Sci., 2018, 430, 263-272.

21 L. Cui, X. Ding, Y. Wang, H. Shi, L. Huang, Y. Zuo and S. Kang, Appl. Surf. Sci., 2017, 391, 202-210.

22 P. Xia, B. Zhu, B. Cheng, J. Yu and J. Xu, ACS Sustainable Chem. Eng., 2017, 6, 965-973.

23 L. Liu, Y. Qi, J. Lu, S. Lin, W. An, Y. Liang and W. Cui, Appl. Catal., B, 2016, 183, 133-141.

24 W.-K. Jo and N. C. S. Selvam, Chem. Eng. J., 2017, 317, 913-924.

25 A. M. Ganose, M. Cuff, K. T. Butler, A. Walsh and D. O. Scanlon, Chem. Mater., 2016, 28, 1980-1984.

26 Y. Yang, F. Zhou, S. Zhan, Y. Liu and Y. Yin, J. Inorg. Organomet. Polym. Mater., 2016, 26, 91-99.

27 Z. Jiang, F. Yang, G. Yang, L. Kong, M. O. Jones, T. Xiao and P. P. Edwards, J. Photochem. Photobiol., A, 2010, 212, 8-13.

28 F. Fina, S. K. Callear, G. M. Carins and J. T. Irvine, Chem. Mater., 2015, 27, 2612-2618.

29 A. Alzamly, M. Bakiro, S. H. Ahmed, S. M. Sallabi, R. A. Al Ajeil, S. A. Alawadhi, H. A. Selem, S. S. M. Al Meshayei, A. Khaleel and N. Al-Shamsi, J. Photochem. Photobiol., A, 2019, 375, 30-39.

30 I. Sharma, G. K. Tripathi, V. K. Sharma, S. N. Tripathi, R. Kurchania, C. Kant, A. K. Sharma and K. Saini, Cogent Chem., 2015, 1, 1076371.

31 X.-J. Wen, C. Zhang, C.-G. Niu, L. Zhang, G.-M. Zeng and X.-G. Zhang, Catal. Commun., 2017, 90, 51-55.

32 M. J. Akhtar, M. Ahamed, S. Kumar, M. M. Khan, J. Ahmad and S. A. Alrokayan, Int. J. Nanomed., 2012, 7, 845.

33 J. Liu, T. Zhang, Z. Wang, G. Dawson and W. Chen, J. Mater. Chem., 2011, 21, 14398-14401.

34 S. Vadivel, B. Paul, D. Maruthamani, M. Kumaravel, T. Vijayaraghavan, S. Hariganesh and R. Pothu, Mater. Sci. Energy Technol., 2019, 2, 112-116.

35 Y. Bai, P.-Q. Wang, J.-Y. Liu and X.-J. Liu, RSC Adv., 2014, 4, 19456-19461.
36 S. Vadivel, M. Vanitha, A. Muthukrishnaraj and N. Balasubramanian, J. Water Proc. Eng., 2014, 1, 17-26.

37 X. Li, C. Niu, D. Huang, X. Wang, X. Zhang, G. Zeng and Q. Niu, Appl. Surf. Sci., 2013, 286, 40-46.

38 K.-L. Li, W. W. Lee, C.-S. Lu, Y.-M. Dai, S.-Y. Chou, H.-L. Chen, H.-P. Lin and C.-C. Chen, J. Taiwan Inst. Chem. Eng., 2014, 45, 2688-2697.

39 J. Wu, Y. Xie, Y. Ling, Y. Dong, J. Li, S. Li and J. Zhao, Front. Chem., 2019, 7, 649.

40 W. Cui, W. An, L. Liu, J. Hu and Y. Liang, J. Hazard. Mater., 2014, 280, 417-427.

41 S. Kumar, N. L. Reddy, A. Kumar, M. V. Shankar and V. Krishnan, Int. J. Hydrogen Energy, 2018, 43, 3988-4002.

42 T. Kanagaraj, S. Thiripuranthagan, S. M. K. Paskalis and H. Abe, Appl. Surf. Sci., 2017, 426, 1030-1045.

43 Z. Liu, B. Wu, Y. Zhao, J. Niu and Y. Zhu, Ceram. Int., 2014, 40, 5597-5603.

44 J.-C. Wang, H.-C. Yao, Z.-Y. Fan, L. Zhang, J.-S. Wang, S.-Q. Zang and Z.-J. Li, ACS Appl. Mater. Interfaces, 2016, 8, 3765-3775.

45 A. Kumar, K. L. Reddy, S. Kumar, A. Kumar, V. Sharma and V. Krishnan, ACS Appl. Mater. Interfaces, 2018, 10, 15565-15581.

46 R. Uma, K. Ravichandran, S. Sriram and B. Sakthivel, Mater. Chem. Phys., 2017, 201, 147-155.

47 L. Huang, H. Xu, Y. Li, H. Li, X. Cheng, J. Xia, Y. Xu and G. Cai, Dalton Trans., 2013, 42, 8606-8616.

48 H. Ji, X. Jing, Y. Xu, J. Yan, H. Li, Y. Li, L. Huang, Q. Zhang, H. Xu and H. Li, RSC Adv., 2015, 5, 57960-57967.

49 X. She, H. Xu, H. Wang, J. Xia, Y. Song, J. Yan, Y. Xu, Q. Zhang, D. Du and H. Li, Dalton Trans., 2015, 44, 7021-7031.

50 S. Vadivel, S. Hariganesh, B. Paul, S. Rajendran, A. HabibiYangjeh, D. Maruthamani and M. Kumaravel, Chem. Phys. Lett., 2020, 738, 136862.

51 S. Vadivel, S. Hariganesh, B. Paul, G. Mamba and P. Puviarasu, Colloids Surf., A, 2020, 592, 124583.

52 M. Jiang, Y. Shi, J. Huang, L. Wang, H. She, J. Tong, B. Su and Q. Wang, Eur. J. Inorg. Chem., 2018, 1834-1841.

53 A. Bhirud, S. Sathaye, R. Waichal, C.-J. Park and B. Kale, J. Mater. Chem. A, 2015, 3, 17050-17063.

54 P. Kumar, A. Kumar, M. A. Rizvi, S. K. Moosvi, V. Krishnan, M. Duvenhage, W. Roos and H. Swart, Appl. Surf. Sci., 2020, 145930.

55 M. Yan, Y. Wu, F. Zhu, Y. Hua and W. Shi, Phys. Chem. Chem. Phys., 2016, 18, 3308-3315.

56 K. H. Leong, Z. Z. Tan, L. C. Sim, P. Saravanan, D. Bahnemann and M. Jang, ChemistrySelect, 2017, 2, 84-89.

57 T. Jia, M. Liu, D. Yu, F. Long, S. Mo, Z. Deng and W. Wang, Nanomaterials, 2018, 8, 313.

58 Y. Zang, L. Li, Y. Xu, Y. Zuo and G. Li, J. Mater. Chem. A, 2014, 2, 15774-15780.

59 W. Y. Teoh, J. A. Scott and R. Amal, J. Phys. Chem. Lett., 2012, 3, 629-639.

60 Y. Jiang, W.-N. Wang, P. Biswas and J. D. Fortner, ACS Appl. Mater. Interfaces, 2014, 6, 11766-11774. 